\title{
THE CHALCIDOID PARASITES OF THE COMMON HOUSE OR TYPHOID FLY (IUSCA DOMESTICA LINNAEUS) AND ITS ALLIES.
}

I. Reconstruction of the Chalcidoid Genus Nasonia Ashmead of the Fanily Pteronalidae, with Description and Biology of Nasonia brevicomis Ashuead, species nova, its 'Type Species froni Illinois.

BY A. A. GIRAULT AND GEORGE ETHELBERT SANDERS, UNIVERSITY OF ILLINOIS.

\section{Introduction.}

DURING the course of some investigations concerning the economy and biology of the common house, or typhoid fly as it is now being more appropriately called,Musca domestica Limnaens - carried on in the insectary of the Office of the State Entornologist of Illinois in the late summer and early fall of 1908, a quite unexpected abundance of a number of hitherto unnoticed or little known parasites of that host and other's of the higher Diptera occurred, among which three generic forms predominated - Spalangia Latreille, Muscidifurax Girault and Sanders MS. ${ }^{1}$ and Nasonia Ashmead, all of the family Pteromalidae. The latter genus is now under consideration. In this paper, from a large number of specimens of both sexes, the genus is redescribed in detail and its type species described as new under the name originally given it by the late Dr. Ashmead (Ashmead, 1904). We enter into the status of the genus and its sole species beyond. Such biological facts as were learned concerning it are also incorporated herewith.

In the series of papers to follow, the genera of the parasites met with during the investigation are considered in detail, and finally, a list of the Chalcidoid parasites of the world's Muscideous Diptera is given, as well as a summary of the whole.

\section{II istory and Description of the Genus.}

The genus Nasonia was based on specimens collected at Algonquin, Illinois, in 1894 and 1895 and sent to the United States National Museum by Dr. William A. Nason in whose honor it was named. It was proposed and described by Ashmead in 1904 (l. c.) in a table of the genera of the pteromaline tribe Eutelini and the undescribed Nasonia brevicomis was named in connection with it as type. The generic description is as follows, extracting from the table:

1 Described in the third paper of this series. 
Pteromalids with abdomen sessile, ovate, shorter than the thorax; metanotum not short, with spiracular sulei, median and lateral carinae, its spiracles oval; antennae 12- to 13-jointed, rather short, flagellum subclavate, the pedicel long and obconieal, the funicle joints wider than long, inserted rentrad of the middle of the face about on an imaginary line drawn between the rentral ends of the eyes; thorax long; head with a broad vertex bearing large ocelli in an acute triangle; pronotum with the cephalic margin aente; marginal rein hardly longer than the stigmal rein.

The genus lay next to Platyterma Walker and Mesopolobus Westwood from both of which it is separated in the table by the much shorter abdomen and its orate shape.

We aceept this genus, and especially the species under protest and merely because it is the wisest thing to do under the circumstances. From the standpoint of nomenclatorial science, the genus is proposed in an inexcusable manner; aside from opinions and codes which do not as yet remedy effectually this kind of systematic obstruction, of itself, the generic description has no specific characters in it and not without imagination is it thinkable that the type species is also described by it. If one wishes to hold that the species is described by it, however, he must admit at once that since the time of Limnaeus, no improvements have been made in descriptive work, besides naïvely overreaching his own common sense. The code should prevent future cases of this kind.

The position of Nasonia in the Ashmeadean tribe Eutelini of the Pteromalinae is not altogether tenable, for the spiracular sulei are obsolete or subobsolete, which would seem to ally the genus with the tribe Roptrocerini of the subfamily Merisinae. For the present, howerer, we leave the genus in the position originally ascribed to it.

\section{Family PTEROMAIIDAE. \\ Subfamily Pteromalinae. \\ Tribe Eutelini.}

Genus Nasonia Ashmead.

(Type: Nasonia brevieornis Ashmead, species nova, described beyond.)

Normal position; taken from the type species.

Female: Normal in size or stature and aspect for the tribe; size very variable; moderately robust, metallic aencous, sheened.

Head (cephalic aspect) elliptical-oval with the long axis latero laterad, that is wider than long the eyes forming the apices, slightly bilobed, the median line of the face obtusely concaved or impressed, in which impression lie the scapes, the serobes 
obsolete; face broad; clypeus small, subquadrate, its ventral (apical) margin truncate, its sutures distinct; immediately rentrad of the antennal insertions, along the median line between them and the clypeus is an obtuse convexity (frontal prominence); genal sulcus obsolete; (lateral aspect) face subconvex, the genae nearly as long as the eyes, romded, the scape of the antemae not reaching to the apex of the vertex or to the cephalic ocellus; eyes ovate, not in the direct lateral aspect, practically hairless; (dorsal aspect) head about two and a quarter times wider than long, the vertex broad, its cephalic margin broadly emarginate at the meson, the occipital margin obtuse, nearly straight; eyes wide apart, the ocelli in a flat, obtuse-angled triangle, not especially near the occipital margin and clistant from the eyes. Head somewhat wider than the widest part of the thorax. Antennae inserted slightly below (rentrad) of the middle of the face, just dorsad (above) of a slight transverse facial prominence, slightly above (dorsad) an imaginary line drawn between the rentral ends of the eyes, but still ventrad of a line drawn through the middle of the eyes or not half way up the eye margins, compact and short, the flagellum clavate, the pedicel much longer than the proximal funicle joint, the funicle joints all wider than long, excepting perhaps the first, with two ring-joints, a 3 -jointed chub and a 6 -jointed funicle and but moderately pubescent (Fig. 1). Right mandible t-dentate, the left 3 dentate, nearly as in Stenomalus Thomson (1S7S). (Fig. 2.)

Pronotum visible, rounded, narrowed mesad, about a third the length of the mesoscutum, its cephalic margin subacute. The mesoscutum with the parapsidal furrows incomplete, but extending from the cephalic margin for more than half the length of the mesoscutum; from lateral aspect, thorax broadly, flatly
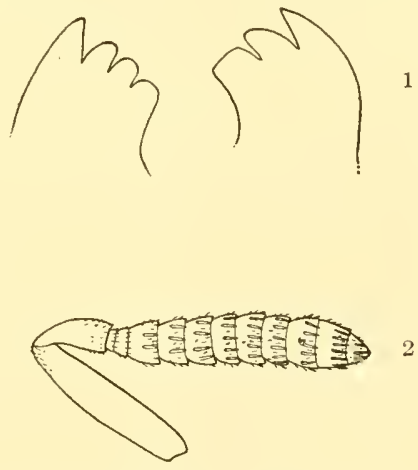

Fig. 1. Antenna of Nasonia brevicornis Ashmead, female, greatly enlarged (pubescence omitted, excepting large setae).

Fig. 2. Mandibles of Nasonia brevicornis Ashmead, female, greatly enlarged, showing dentation. convex; axillae widely separated; scutellum with a narrow, transverse, grooved line at the base of its apical (caudal) fourth, composed of minute punctures; median and lateral carinae of the metathorax distinct, the latter curved; spiracular sulcus absent; spiracle of metathorax subreniform, somewhat near the postscutellar margin, its axis oblique; metathorax punctate, with little or no neck.

Abdomen sessile, widest at the apex of the second segment (1st body segment), 
robust, flat above, eonic-ovate, shorter than the thorax and variably convex below (ventrad), sometimes not noticeably so; segment 2 nearly a half the total length of the abdomen, segment 3 next longest but only a third the length of segment 2, segments 4 and 5 subequal, very short, both together not quite as long as segment 3 ; segment 6 slightly longer than 4 or 5 , the latter being intermediate in size between the two; segunents 7 and $S$ minute, the latter conic.

Wings hyaline, the fore wings (Fig. 3) rounded apically, without marginal
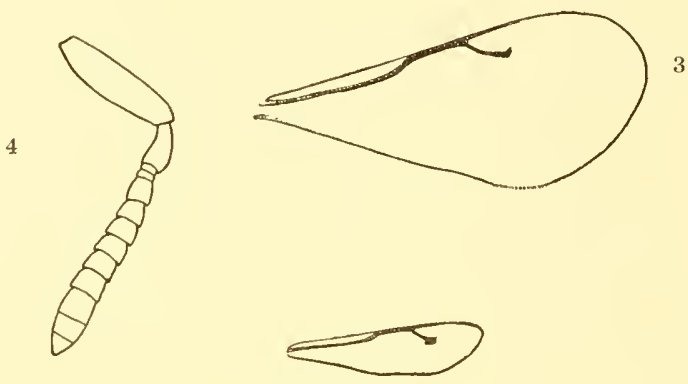

5

Fig. 3. Fore wing of Nasonia brevicornis Ashmead, female, greatly enlarged (discal cilia onitted).

Fig. 4. Antenna of Nasonia brevicornis Ashmead, male, greatly enlarged; pubescence omitted.

Fig. 5. Fore wing of Nasonia brevicornis Ashmead, male, greatly enlarged, (discal cilia omitted; drawn on same scale as female wing.

fringes, but usually ciliate in the disk, naked, however, proximad of the apical end of the submarginal vein, the latter over twice the length of the marginal vein which is slightly longer than the postmarginal vein and somewhat more so than the stigmal vein; postmarginal rein slenderer, slightly longer than the stigmal vein which is slightly curved with a small, truncate club and uncus. Submarginal vein of hind wings thickened and confluent with the costal margin proximad, for not half its length, then descending, twice or more longer than the marginal vein, the disk of the wing ciliate, and the eaudal margin with short eilia.

Tarsi 5-jointed, the tibial spurs single. Marginal vein of fore wing normal, not thickened, uniform in width.

Last joint of maxillary palpi as long as the combined lengths of the other 3 joints, or nearly. Labial palpi 3-jointed, the intermediate joint minute, the others subequal but the distal joint somewhat the longest of either of the three.

Male: The same in general bodily structure as the female, but slenderer, smaller, the fore wings entirely differently shaped and smaller, being much the broadest just 
apicad of the postmarginal vein in the female, but in the male slenderer and subfuscous, not subpyriform, rather, strongly clavate. Different in aspect.

Head (cephalic aspect) not noticeably impressed along the meson, more convex; (lateral aspect) the eyes more rounded and proportionately larger, the genae not as long as the eyes, the seape reaching to the apex of the vertex or slightly beyond; (dorsal aspeet) head the same but much wider than the greatest width of the thorax, at least a third or more wider; antennae inserted slightly more dorsad, not quite half way up the eye margins, the flagellum slenderer, the funicle joints not quite. as wide in proportion to their length as in the female, the proximal funicle joints quadrate or subquadrate (Fig. 4); mandibles as in the female. Genal sulcus absent.

Pronotum slightly longer in proportion to the length of the mesoscutum; the transverse groove before the apex of the scutellum more distinet; the lateral earinae of the metathorax complete, distinct, eurved, the median carina distinet, but faint; metathoracic spiracles slightly smaller, farther caudad, elliptical. Metathorax punctate.

Abdomen the same, but depressed, concave dorsad (dead specimens), variable in length but usually not exceeding that of the thorax and from dorsal aspect ovate; segment 2 the longest and broadest segment, but not quite as long in relation to the length of the abdomen as in female, all of the eaudal margins of the segments straight; segments 4 and 5 subequal, both together about equal to the length of segment 3 , which is not quite a third of the length of segment 2 ; segments 6,7 , and 8 longer than segment 4 or 5 , but not as long as segment 3 , all subequal, the 8 th the longest of the three and conic in shape. Genitalia exserted in death.

Fore wings (Fig. 5) different, more pubescent or ciliate in the apical half than in the female fore wing, subclavate, with a dusky hue due to the thick discal cilia and slightly fumated and opalescent. Venation the same but the knob of the stigmal vein is larger, more dilated.

A genus of rather short and stout parasites, not unusual for its family, exeepting in the case of the wings of the male. If placed in the tribe Roptrocerini, it would be nearest to Uriella Ashmead, but differing from that genus in the shorter, broader, differently shaped abdomen, the entirely different, stouter and shorter, antennae, in the longer third abdominal segment and antennal pedicel, the shorter postmarginal vein, the larger metathoracic spiracles, the presence of the lateral carinae or folds of the metathorax and possibly in mandibular characters, those of Uriella being perhaps 3-dentate (Ashmead, 1S96). 'The genus has also many of the characters of Mormoniella Ashmead of the tribe Rhaphitelini, another genus without a described type species. 


\section{IIost Relations of the Genus.}

Heretofore, nothing has been recorded concerning the hosts of this genus. Beyond, we give a recorl of a large series of rearings of the type species, all of which may be included in the following general statement: 'The genus attacks gregariously or "socially" the puparia of three or four genera of the higher Diptera - Chrysomyia (macellaria), Luritia, Musca (domestica), Sareophaga and Phormia (regina); also it may be found to attack (alliphora. All of these are forms of economic importance. In nature, the genus attacks mostly (hrysomyia (marellaria) and Phormia (regina), so far as is known. In confinement, it readily attacked the puparia of Cynomyia cadaverina Desvoidy, in addition to the others. Though gregarious, it is an external parasite, the larvae not penetrating the host's body.

\section{Distribution of the Genus.}

This genus appears to be very abundant, at least in the state of Illinois. It has not however been recorded from more than two localities in that state, namely Algonquin (Nason, 1906) where it was first discovered and Urbana and Champaign, two adjoining towns farther south in the state.

\section{The Type Species of the Gemus.}

Nasonia brevicomis Ashmead, as previously stated, has never been rescribed, merely being named in parentheses as type of the genus. Other than that, it has been mentioned but once in the literature, namely by Nason (1906), who records its first collection. Heretofore, its status has been that of a nomen mudum, or nearly.

1. Nasonia brevicornis Ashmead, species nova.

Aslumead, 1904, pp. 317-318.

Nason, 1906, p. 156.

Nomal position.

Female: Length, very variable; maximum, $2.30 \mathrm{~mm}$; minimum, $1.0 \mathrm{~mm}$.; range, $1.3 \mathrm{~mm}$; average, $1.75 \mathrm{~nm}$.; moke, $2.0 \mathrm{~mm}$. Usually stout.

General color metallic dark brassy green, the abdomen dark, less metallic, shining, the metathorax dull; seape and pedicel fuscous, the latter often much darker, especially dorsad; flagellum neutral blackish, dusky; legs fuscous with the following exceptions - coxae concolorous, metallie, the intermediate ones often fulvous at the apex or the entire joint dull blackish; apical tarsal joints dusky; most of the dorsal aspect of the caudal femora blackish. Eyes garnet; ocelli pinkish; tegulae 
fulvous. Wings hyaline, the venation fulvous. Ventum concolorous, or sometimes, including the thoracic pleura, with a steel bluish color.

The whole of the head densely reticulated with polygonal figures similar to that of the mesothoracic dorsum and about of the same roughness as the surface of the eye, the surface of the clypeus, howerer, longitudinally rugulose; ocelli oval, the lateral ones with their apices oblique, the cephalic one with its axis transverse (laterolatera(); lateral ocelli about the same distance from the cephalic ocellus as they are from the respective eye margins, but much wider apart from each other.

Pro- and mesonota polygonally sculptured like the head, not punctate, the former not as broad as the latter; cephalic and caudal margins of the scutum straight, the caudal margin slightly broken at the axillae; the axillar sutures, as usual, widening caudad and transverscly carinate; scutellum widest at the transverse grooved line or suture, somewhat acom-shaped, at its base against the mesoscutum, impressed transversely the impression or suture bearing short longitudinal carinae, closer and shorter than those on the surface of the mesopostscutellum; the latter sclerite transverse, slightly convexly curved, widening laterad, impressed and with longitudinal ridges, its caudal margin carinated; scutellum not as long as the scutum, but nearly so; cephalic margin of the mesopostscutellum carinated or acute in the direct dorsal aspect; sculpture of the metanotum coarser, punctate, especially the disk or that portion included between the lateral carinae; metanotum not as long as the scutellum but as wide as the widest portion of the mesothorax, its pleurum bearing a moderately large clump of stiff white hairs ventrad of the spiracle, its caudo-lateral angles subacute and at the caudal end of the median carina is a slight rising or neck just cephalad of which is a transverse line of a few large punctures or obscure depressions, extending from side to side. Pleura of thorax sculptured as the metanotum, but more coarsely, the intermediate and cephalic coxae nearly smooth, the caudal coxae reticulated. Hairs on body sparse, no conspicuous pubescence.

Abdomen delicately, minutely polygonally reticulated; tip of ovipositor fuscous. Proximal joint of the caudal tarsi longest, the apical joint next longest, the second joint third in length about a third shorter than the proximal joint and the third and fourth joints subequal, shortest, not quite half the length of the proximal joint. Candal halves of segments 5-S of abdomen with fine pubescence, less and less so on proximal segments.

Antennae short, stout, clavate, not compressed, flagellum (funicle + (lub) hispidi-pubescent, the pubescence dense cnough to conceal the true surface of the joints or the sculpture of them. Scape slightly compressed, its margins nearly straight, very slightly convexed at their centers and slightly narrower distad, bearing minute, fine, 
scattered hairs, moderately stout and as long as the united lengths of the pedicel, ring-joints and the 3 proximal funiele joints or about half the length of the flagellum (inchuding pedicel); scape as long as the funicel and twice the length of the club. Pedicel narrower, obconic, with a moderately long, tapering neck, distinctly twice longer than the proximal funicle joint, slightly longer than the united lengths of the two proximal funicle joints, and much longer than any of the following joints; ringjoints small, the first smaller than the seeond, about half its size, the second distinetly three times smaller than the proximal funicle joint; funicle compact, the joints all wider than long and closely mited, gradually widening distad and all about subequal, the funicle stout and nearly cylindrical; joints 1 and 2 of the funicle more nearly equal, longest, subquadrate; joint 3 slightly wider and shorter, joints 4, 5, 6 nearly equal, widest and shortest, each about a fourth shorter and a third wider than joints 1 or 2 of the funicle; club compact, wider, conic-ovate, not quite half as long as the funicle, its basal joint somewhat longer and slightly wider than the distal funicle joint, the intermediate joint longer but narrowing distad, the apical joint conic, distinctly shorter. Pubescence of pedicel and ring-joints longer and somewhat denser than that of the seape, but inconspicuous, that of the funcle and club similar, much denser, distinct and each joint has distinet longitudinal earinae, which appear in balsam-mounted specimens, high-power, as transverse rows of stout, flattened hairs attached eaudad of the apical half of each respective joint and which may also give the appearance under high-power of whitened, longitudinal sulci. The pubescence of the flagellum is arranged in about two principal transverse rows, but not regularly so. Antennal bulbs separate for over their own widths.

Left mandible 3-dentate, the inner (mesal) tooth broad, truncate, the intermediate tooth obtuse, conic, the outer (lateral) tooth acute, slightly the longest. Right mandible 4-dentate, the mesal tooth broadest, broadly rounded at apex, the two intermediate teeth subequal, short, small, curved, obtuse, the outer (lateral) tooth acute, longest.

(From 447 specimens, $\frac{2}{3}$-inch objective, 1-inch optic, Bausch and Lomb.)

Male: Length, very variable; maximum, $2.0 \mathrm{~mm}$; minimum, $0.60 \mathrm{~mm}$; range, $1.4 \mathrm{~mm}$; average, $1.32 \mathrm{~mm}$; mode, $1.3 \mathrm{~mm}$. Usually appearing a third smaller than the female.

Aspect different, lighter in color, more brassy, metallic and green, the abdomen depressed, ovate to fusiform, usually concave dorsad, sometimes flat; rounded ventrad, rarely convexed, shorter than the thorax; the vertex deeidedly brassy; legs and antennae honey-yellow, excepting the coxae; clypeus less longitudinally rugulose, glabrous at the extreme apical meson, wider than long; wings smaller, more densely 
ciliate, somewhat clouded and with a distinct fumated area just caudad of the marginal vein and the curved distal portion of the submarginal vein; grooved, punctate transverse line of the scutellum curved convexly at the meson; metathorax with a slightly larger neck. Eyes sometimes a brilliant carmine.

Antennae about the same shaje as in the female, but slenderer, less densely and more softly pubescent, the funicle joints relatively longer, the apical club joint more pointed, the scape relatively stouter.

Ring-joints more nearly equal, the second longer than the first, however. First funicle joint quadrate, sometimes longer than wide; pedicel stouter and shorter, but distinctly much longer than the proximal funicle joint. Longitudinal carination present on the club only.

(From 143 specimens, $\frac{2}{3}$-inch objective, 1-inch optic, Bausch and Lomb.)

Viewed with a hand-lens (Coddington, $\frac{1}{2}$-inch, Bausch and Lomb), the female is a deep rich dark green, the abdomen nearly black, the head and thorax dorsad reflecting brassy scintillations, in some lights entirely brassy; in the ventral aspect and also the lateral, the thorax appears bluish; the antennae dark, the scape and pedicel a rich brown, the legs mostly brown with darker femora. On the contrary, the males appear a brilliant bright metallic green, reflecting brassiness, the antennae and legs light yellowish brown, the wings small, clouded, with a soiled appearance; the ventral aspect is the same but with slight traces of metallic bluish. 'The male is noticeably more brilliant and bright than the female, which is somewhat sombre.

The appearance of the two sexes to the naked eye is also characteristic. The females appear as comparatively large, stout, blackish gnats, with large, clear wings; the males as a rule appear to be a half size smaller, the wings less conspicuous and clouded, often not noticed at all, the bright greenness of the body and the light yellowish antennae and legs being characteristic; further the females are distinguished by their comparative stoutness, the stout abdomen (and its usually triangular shape, lateral aspect), while the abdomen of the male is flat, with the penis exserted and curved. In life, however, it is not so easy to distinguish the sexes, as the abdomen of the male is then decidedly stouter, thicker dorso-rentrad and the genitalia concealed. As a matter of fact, the insect has a different appearance in life, and at a casual glance, there is not very much difference between the sexes in abdominal characters. The parasites are also noticeably larger in life than in death, and the abdominal segments are then fully extended; at a casual glance the males appear to be wingless. The following descriptive notes were made from specimens recently emerged (after 2 hours) and stupefied with chloroform: Female - Segment 2 of the abdomen longest, but only a fourth the total length of the abdomen; 3 next in 
length, a third the length of 2 ; segments $4,5,6$ and 7 subequal, slightly shorter than 3 ; segment 8 conic, shorter; abdomen flatly eonvex dorsad, about as long on the head and thorax combined. Male.-Abdomen nearly as in the female, stout, as long as the combined lengths of the head and thorax; segments 2, 3 and 4 subequal, and 5, 6 and 7 subequal, slightly shorter, the 7 th somewhat shorter than 6 , and segment $S$ still smaller, conic. Highly convex above and flatly so ventrad; sometimes larger in proportion to the body than in the female.

Both sexes vary considerably in size as shown by the measurements given, so that size is not always indicative of sex. A number of males and a few females bave been seen which were not much larger than some Mymaridae, not easily noticed with the naked eye, though distinet when once seen.

Types:- 'Type No. 12,318, I. S. National Musem, ${ }^{1}$ Washington, D. C. Cotypes, - 2 f's in the Nason Collection (Illinois State Laboratory of Natural History, Urhana, Illinois), Algonquin, Illinois, May 11, July 3, 1895. Homotypes-Acession No. 40239, Illinois State Laboratory of Natural Ilistory, Urbana, 12 万’'s, 126 우's, tagmounted, and $2 \sigma^{7}$ 's, 2 ㅇ's in collection U. S. National Museum, Washington, D. C., also tagmounted.

Described from the following series of 640 specimens, nearly all of which were reared from various muscid puparia in the insectary of the Oflice of the State Entomologist of Illinois, at Urbana, Illinois, during 1908, and now in the eollections of the Illinois State Laboratory of Natural History; unless otherwise stated the specimens are mounted on tags. All of the host material was eollected in the immediate vicinity of Urbana or its twin town, Champaign, Illinois, Champaign County:

(1.) Four females reared September 9th and two females September 11th, in a eage containing decomposed chicken viscera obtained from the city garbage grounds on August 22nd and infested with the maggots of the following Diptera Chrysomyia macellaria (Fabricius), Sep. 7th, Calliphora erythrocephala (Meigen), Sep. 11th, and Sarcophaga speeies "k"'2 (Sep. 22nd); one of the females observer ovipositing into a puparium of the Chrysomyia on the 9th of September; Accession Nos. 39912 (3 f 's xylol-balsam, 1 o head, 1 slicle) and 39921 ( 2 o 's); the latter is. sued in company with a single female of Pachycrepoidens dubius Ashmead MS. ${ }^{3}$ 1 female eaptured at large in insectary around fly breeding-cages, September 12th; Accession No. 39925 ( 1 \%). (3.) 7 females captured in the insectary same date

"1 1 \%, tagmounter, from the Nason collection, Algonquin, Illinois, labelled 6.18.95-114 and 4595 . There are also 2 other tagmounted females from the same collection, designated as cotypes and respectively labelled6.24.95-114 and 4593; and 6.2.95-114 and 4644. These'label numbers were made by Dr. Nason."

2 Species nova; designated thus for convenience. The Diptera mentioned throughout were determined by C. A. Hart.

3 This species is described in the second paper of this series. 
around the breeding-cages; Accession Nos. 39926, 3992\%, 3992S, 39933, 3993\%, 39935 and 39936 ( 7 우's). (4.) $100^{7}$ 's, 1 female reared September 12 th from putrefied meat from which the following host Diptera were also obtained-Chrysomyia macellaria (Fabricius), large numbers, Aug. 27th to Sep. 12th; Phormia regina (Meigen), large numbers, August 26th to Sep. 12th; Sarcophaga species "k" 1, 5 specimens, Sep. 6th and 7th; Mrsea domestica Limnaeus, 1 female, August 29th; 1 female of brevicomis was observed to emerge from a puparium of the Phormia. Accession No. 39938 (10 o $^{\text {'s }}$ s, 1 우). (5.) 2 우's captured in insectary around fly breeding-cage, Sep. 13th; Accession Nos. 39956 and 39958 (2 o's). (6.) 7 o's captured Sep. 9th about fly breeding-cages in insectary; Aceession No. 3995\% (7 ㅇ's). (7.) $3 \mathrm{O}^{7}$ 's, 3 क्?'s removed from the puparia of Phormia regina, Sep. 14th, the hosts reared in company with Chrysomyia macellaria, in large numbers from decayed meat; Accession No. 39959, (3 O ' fly breeding-cages in insectary, Sep. 10th; Accession Nos. 39961, 39962, 39964. 39966 and $3996 \%$ (5 ㅇ's). (9.) 1 ऊ', 24 ㅇ's + 22 reared Sep. 14th from an infested eadaver of a small pig from which the following possible bosts were reared - Musca domestica (Aug. 26 to Sep. 1, in large numbers), Chrysomyia macellaria (few, Aug. 27th to 30th), Phormia regina, Lucilia caesar (Linnacus), Lucilia sericata (Meigan) - Aug. 30th to Sep. 6th, the former abundant; Accession No. 3997尺 (1 24 오's). (10.) 10, 6\%'s, reared in confinement from a puparium of Musca domestica, Sep. 25th, the progeny of a single female; Accession No. 40140 (1 $\sigma^{7}$, 6 우's). (11.) $9 \mathrm{~J}^{7} \mathrm{~s}, 12$ 오's, reared in confinement from $\mathrm{S}$ puparia of Musca domestica, Sep. 25th, the progeny of 2 females; Accession No. 40141 (9 J's, 12 우's). (12.) $6 \delta^{7} \mathrm{~s}, 10$ 오's reared in confinement from the puparia of the same host, Sep. 26th, the progeny of 7 females; Accession No. 40142 (6 $\sigma^{7}$ 's, 10 क 's). (13.) 1 female reared Sep. 22nd, from eage containing cadaver of a rabbit exposed for fly infestation and from which was reared the following possible hosts - Phormia regina and Lucilia sericata (Sep. 14th-22nd, the former abundantly), Chrysomyia macellaria (few, Sep. 14th-22nd) and Musca domestica (1 0 , Sep. 22nd); Accession No. 40124 (1 ㅇ). (14.) 5 females reared from a puparium of Phormia regina, Sep. 25th; Accession No. 40147 (5 오's). (15.) 1 male, 11 females reared Sep. 25th from a puparium of Phormia regina; Accession No. $4014 S$ (1 $\sigma^{\top}, 11$ ㅇ's). (16.) 1 우 captured Sep. 10th on fly breeding-cage in insectary; Accession No. 40149 (1 우). (17.) $1 \sigma^{\gamma}, 2$ 옹 reared in confinement Sep. 2Sth from a puparim of Musca domcstica, the progeny of a single female; Accession No. 40151 (1 ठ, 2 우s). (1S.) $2 \sigma^{7}$ 's, 17 오's +4 reared in confinement from 4 puparia of Mrsca domestica, Sep.

1 Species nova; designated thus for convenience. The Diptera mentioned throughout were determined by C. A. Hart. 
28th, all the progeny of a single female; Accession No. 40152 (2 $6^{72} \mathrm{~s}, 17$ \%'s). (19.) $2 \mathrm{O}^{\text {, }} \mathrm{s}, \mathrm{S}$ \% 's reared in confinement from a puparium of Lucilia scricata (Meigen), Oct. 1st, progeny of a single female; Accession No. 40158 ( $2 \mathrm{O}^{7}$ 's, S 8 's). (20.) 3 o7's, 7 क 's reared from a puparium of Phormia, Oct. 2nd; Accession No.

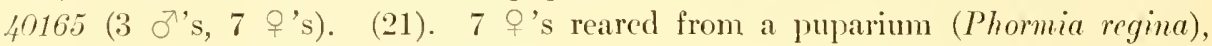
Oct. 13th; Accession No. 40215 (7 ㅇ's). (22). 38 o's, 65 O 's reared in confinement Oct. 20th from 22 muscid puparia (Phormia etc.), all the progeny of a single

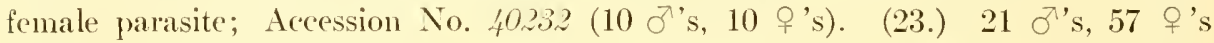
reared in confinement from 17 puparia of Phormia regina (Meigen), Oct. 20th, all the progeny of a single female; Accession No. 40233 (20 \% 's). (24.) 12 37's, 126 's reared Oct. 19th from puparia of Phormia regina (Meigen); Accession No. 40239 (12 O's, 126 ㅇ's). (25.) 1 parthenogenetic female reared Sep. 27th, from Phormia puparia; Accession No. 40260 (1 \%). (26.) 17 on's reared in confinement from a puparium of Phormia regina (Meigen), Oct. 15th, all the progeny of the unfertilized female of the preceding number; Accession No. 40261 $\left(17 \mathrm{O}^{7} \mathrm{~s}\right) . \quad(27)$.1 우 , parthenogenetic parent of the next number, reared from Phormia puparia, Sep. 27 th; Accession No. 40262 (1 + ). (28.) 15 o's reared in confinement from a puparium of Phormia regina (Meigen) Oct. 15th, the progeny of the preceding number; Accession No. 40263 (15 ot's). (29.) 45 ㅇ's + 24 reared from the same hosts as number 9 in preceding, Sep. 15th; Accession No. 41072 ( 45 옹). (30.) 2 o's in the Nason collection each labelled type, "Algoncuin, Illinois, May 11th, July 3rd, 1895"; $1 \mathrm{O}^{7}, 7$ O 's, in the same collection wrongly determined as (Pteromahus) Meroporus calandrae (Howard); ${ }^{1}$ o's, June 9th, 30th, July 3rd, Sep. 5th, 10th, 17th, 1894-1895; O', Aug. 23rd, 1894. In addition, the following specimens were examined and discarded: 22 ot's, 4 ㅇ 's emerging during late September, 1908, from a single puparium of Sarcophaga sp. "e," "2 reared from human excrement exposed for infestation. Altogether, we have critically examined five or six thousand specimens of this species.

\section{Biological Notes.}

During the late summer and early fall of 1908, Nasonia brevicomis Ashmead was exceedingly abundant in the insectary where the fly breeding-cages were located, but we did not have time or opportunity to give sufficient attention to it so that but few breeding experiments were undertaken. 'These few experiments, however,

1 This species is not represented in the Nason collection at all. (Cf. Nason, 1906.)

2 See the previous foot note in regard to this designation. 
brought out one or two points of interest and importance in its life-history and they are considered herewith, together with a number of miscellaneous observations of more or less significance.

In habit, this parasite is stolid and serious, little heeding external influences and disturbances, quietly, persistently giving its whole attention to reproduction. This habit of the adult female allowcd us to breed it with facility; it offers, therefore, an excellent subject for the investigation of the biological problems connected with the parasitic Hymenoptera.

Both sexes crawl quite fast, and the female is able to fly, though crawling appears to be the favorite mode of locomotion; some males walk habitually with the small fore wings extended and directed ventrad, touching the surface upon which the insect happens to be walking over, the hind wings extending normally along the back; but in the majority of cases, this habit does not occur, the wings in their normal position and then not extending farther caudad than the third abdominal segment. The wings of the females are folded flat over the abromen, normally, and extend slightly beyond the abdomein. We have never seen a male in flight, and their wings are non-functional apparently.

If violently disturbed with a camel's hair brush while walking the female simply wriggles free of it, but if the disturbance is continucd, she may simulate death by suddenly falling over on her side or back and drawing in the legs, contintiing for several seconds. On the other hand, on very slight disturbance, she may hop a short distance or assume the same attitude as formerly for several seconds. Apparently this attitude, which is not really the attitude of death, is never long continued and its use to the species is a matter of question. If the females are flung into the air from the end of a brush, they readily take to flight.

At first, we hastily summarize the few special experiments performed with this species.

I. On September 9th, 1908, 50 maggots and 10 puparia of Musca domestica Linnaeus were placed in a quantity of clean horse manure in a glass breeding-jar and 7 females of Nasonia brevicornis were added. The hosts were free from parasites. As a result, reproduction of the parasites occurred and on September 26th, 1908, 6 males and 10 females of the ptcromalid energed from puparia. 'The parasite attacks Musca domestica in confinement.

II. On September 12th, 1908, 8 female parasites were confined separately in small gelatine capsules, each with a single healthy puparium of Musca domestica. Apparent oviposition was observed in each case, but no parasites afterwards appeared; in half the cases the host flies emerged. 
III. On September 13th, 1908, \& female parasites were confined separately in small gelatine capsules, each with a single healthy puparium; of Phormia regina (Meigen); apparent oviposition was observed in each case. As a result, on October 1st, 190S, from one of the host puparia, there appeared 2 males and 8 females of the parasite. Other emergences did not occur. The parasite attacks Phormia regina in eonfinement.

IV. On September 27th, 1908, 12 virgin females of brevicomis, reared separately from puparia of Phormia regina and in no instance accessible to males, were confined separately, each in a small gelatine capsule with a single known healthy puparium of the Phormia; on September 29th at 11:30 A. M., in three cases females were observed ovipositing; on October 15th, 1908, the progeny of two of the virgin females emerged as follows - 17 males (Accession No. 40260, parent and 40261, male progeny) and 15 males (Aecession No. 40262 parent and 40263 , male progeny). Other emergences did not occur, but in three instances the larvae of the parasites were found in the host puparia, all dying, however. Hence, this parasite is parthenogenetic.

'The foregoing experiments unfortunately could not be extended and they merely indicate parthenogenesis (unverified) and the readiness with whieh this parasite attacks its various hosts in confinement.

(To be continued.)

'The Rediscover of Glutops singularis Burgess.- This interesting fly was deseribed by Edward Burgess in the Proceedings of the Boston Society of Natural History, Vol. IIX, p. 322, pl. 1, figs. 2, a, b, c, d, 1878. It was collected by Dr. George Dimmoek at Springfield, Mass., about 1872 near the U'nited States armory, a section of the eity now entirely built over, as are the surroundings for a long distance beyond; it is therefore doubtful if it will again be found near the type locality. 'The Burgess collection was obtained by Dr. C. V. Riley and the type of this species is now in the U. S. National Museum.

On April 18, 1909, Mr. William Reiff captured three males of this long lost speeies, near Purgatory Swamp, Norwood, Mass. Through the kindness of Professor William M. Wheeler one of the specimens has been placed in the New England Collection of the Boston Soeiety of Natural History, and another will be placed in the Museum of Comparative Zoology, Cambridge. Now, that the time of its appearance is known, it is to be hoped that the female will soon be obtained, and perhaps the life history of this peeuliar fly discovered.

C. IV. Johnson. 

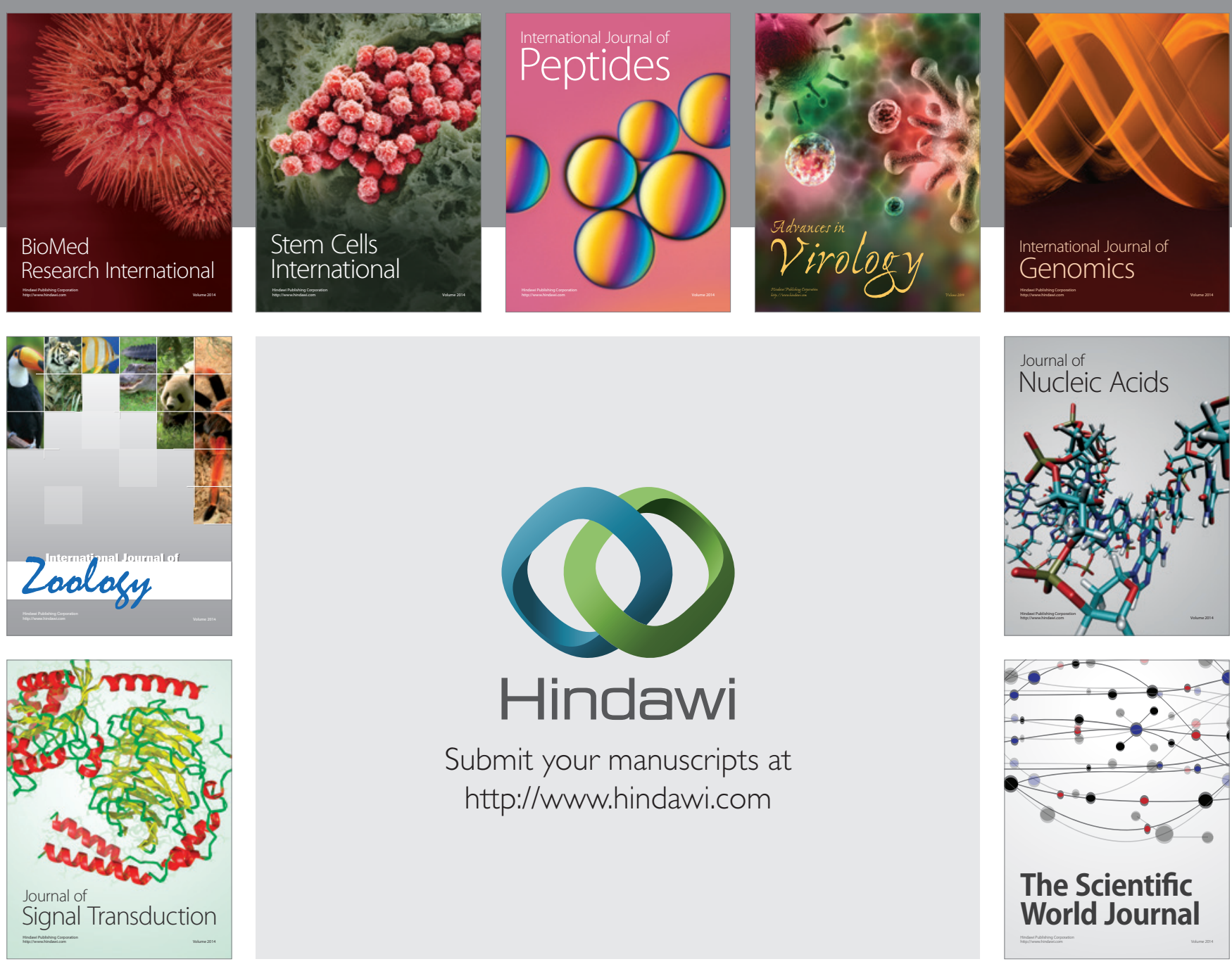

Submit your manuscripts at

http://www.hindawi.com
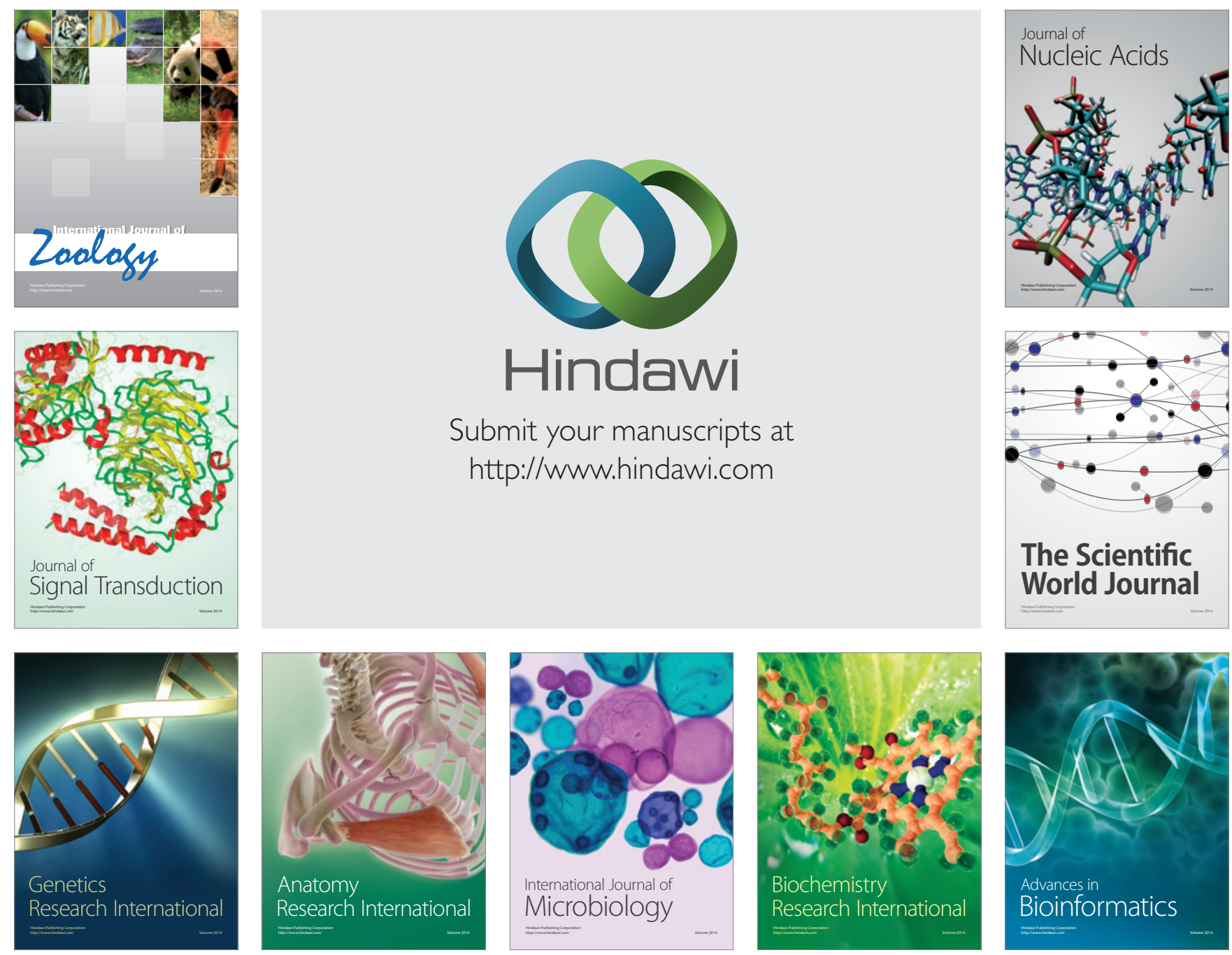

The Scientific World Journal
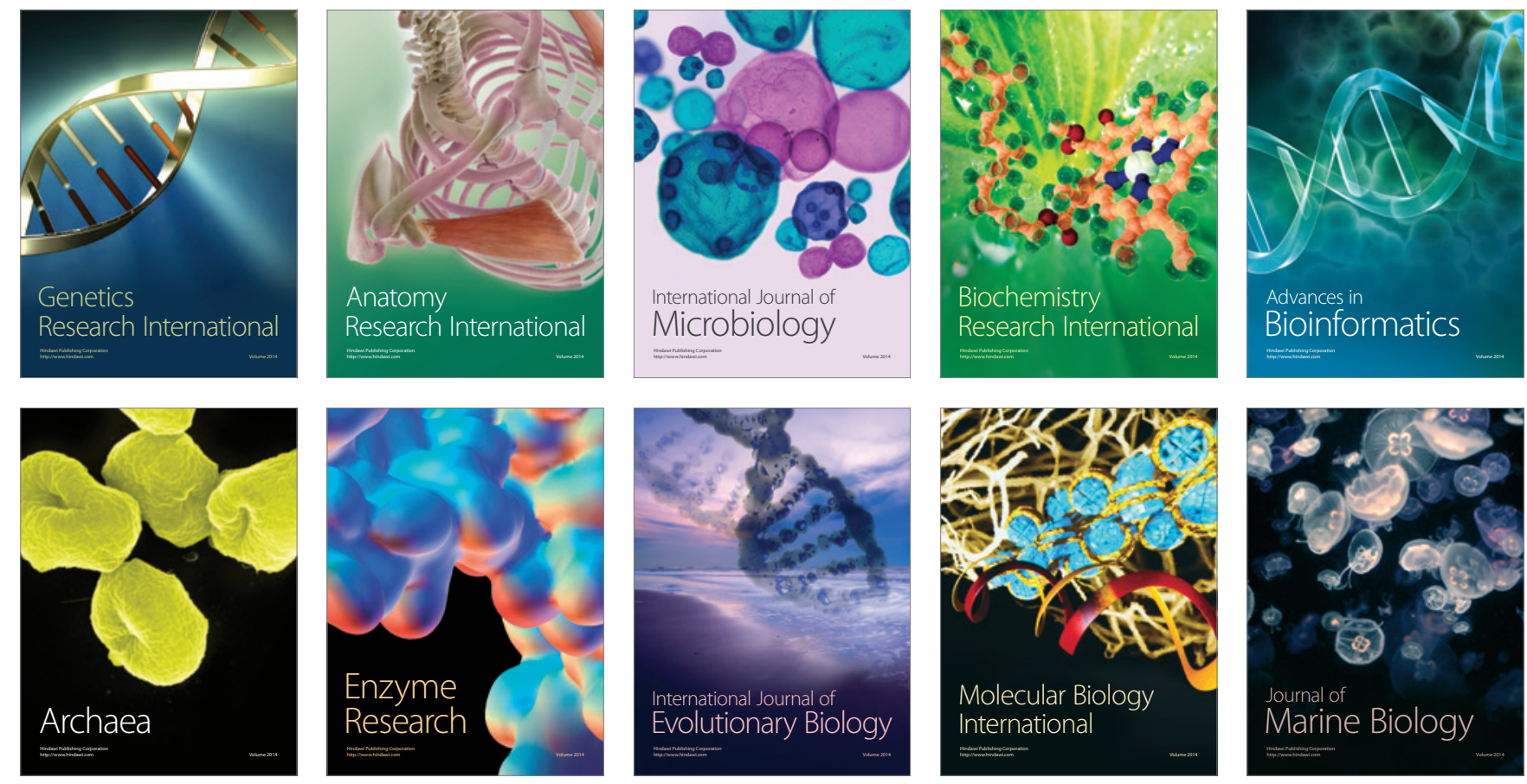